\title{
Activismo, producción de saberes y disputas por el control: la apertura de los archivos de las Fuerzas Armadas en Argentina*
}

Cinthia Balé**

Artículo de investigación sobre el proceso de apertura de los archivos de las Fuerzas Armadas vinculados con las violaciones a los derechos humanos cometidas durante la última dictadura militar en Argentina (1976-1983).

Recibido: 7 de septiembre de 2020

Evaluado: 17 de febrero de 2021

Aceptado: 18 de febrero de 2021

Publicado: 1 de julio de 2021

Citar como:

Bale, C. (2021). Activismo, producción de saberes y disputas por el control: la apertura de los archivos de las Fuerzas Armadas en Argentina. Hallazgos, 18(36), 21-51.

https://doi.org/10.15332/2422409X.6127

\section{Resumen}

La demanda por la apertura de los "archivos de la represión" ha sido una constante en el Cono Sur de América Latina. En Argentina, las Fuerzas Armadas y de Seguridad alegaron durante varias décadas que los

\footnotetext{
* Este artículo es producto de mi investigación doctoral realizada en el marco de una beca otorgada por el Consejo Nacional de Investigaciones Científicas y Técnicas en la Escuela Interdisciplinaria de Altos Estudios Sociales de la Universidad Nacional San Martín, Argentina.

** Doctora en Ciencias Sociales por la Universidad de Buenos Aires, Argentina. Becaria posdoctoral del CONICET con sede en la Escuela Interdisciplinaria de Altos Estudios Sociales de la Universidad Nacional San Martín. Correo electrónico: cinthia.bale@yahoo.com ORCID: https://orcid.org/0000-0002-7300-5254
} 
registros de la represión ilegal no existían o habían sido destruidos. Sin embargo, en 2006, el gobierno de Néstor Kirchner dispuso por primera vez la apertura de los archivos militares con el objeto de relevar documentación que pudiera estar vinculada a las violaciones de los derechos humanos cometidas durante la última dictadura militar (19761983). En este artículo se examina este proceso, haciendo especial hincapié en las estrategias que se implementaron - desde el Ministerio de Defensa - para responder a la demanda social por la "apertura de los archivos" y traspasar la documentación pertinente a la esfera judicial. Se identificarán los alcances y límites de esta política, así como las lecciones que es posible extraer de este proceso para la apertura de otros archivos en Argentina y en otros países de Latinoamérica.

Palabras clave: Archivos; Derechos Humanos; Dictadura; Cono Sur; Fuerzas Armadas; Justicia transicional.

\section{Activism, production of knowledge and disputes over control: the release of the Armed Forces archives in Argentina}

\section{Abstract}

The demand to open up the "archives of the repression" has been a constant in the Southern Cone of Latin America. In Argentina, the Armed Forces claimed for several decades that these records of illegal repression did not exist or had been destroyed. However, in 2006 Néstor Kirchner's administration ordered for the first time to release the military records in order to gather documentation that could be linked to human rights violations committed during the last military dictatorship (1976-1983). This article examines this process, with special emphasis on the strategies that were implemented - from the Ministry of Defense- to respond to the social demand for the "opening of the archives" and to transfer the relevant documentation to the judicial branch. The scopes and limits of this policy will be identified, as well as the lessons that can 
be drawn from this process for the release of other records in Argentina and other Latin America countries.

Keywords: Archives; Human Rights; Dictatorship; Southern Cone; Armed Forces; Transitional justice.

\section{Ativismo, produção de saberes e disputas por controle: a abertura de arquivos das Forças Armadas na Argentina}

\section{Resumo}

A reivindicação pela abertura dos "arquivos da repressão" tem sido uma constante no Cone Sul da América Latina. Na Argentina, as Forças Armadas e de Segurança alegaram por várias décadas que os registros da repressão ilegal não existiam ou haviam sido destruídos. No entanto, em 2006, o governo de Néstor Kirchner ordenou a abertura dos arquivos militares pela primeira vez para coletar documentação que pudesse estar ligada às violações de direitos humanos cometidas durante a última ditadura militar (1976-1983). Este artigo examina esse processo, com ênfase especial nas estratégias implementadas - a partir do Ministério da Defesa - para atender à demanda social de "abertura dos arquivos" e de transferência da documentação pertinente para a esfera judicial. Serão identificados o alcance e os limites desta política, bem como as lições que podem ser tiradas desse processo para a abertura de outros arquivos na Argentina e em outros países da América Latina.

Palavras-chave: Arquivos; Direitos humanos; Ditadura; Cone Sul;

Forças Armadas; Justiça de transição.

La demanda por la apertura de los archivos asociados a graves violaciones a los derechos humanos ha sido una constante en el Cono Sur de América Latina. En la mayoría de los casos, los denominados "archivos de la represión” - es decir, documentos producidos por las Fuerzas Armadas o de Seguridad que dan cuenta del accionar represivo ilegal-se 
mantuvieron deliberadamente en secreto durante largos años o fueron destruidos por los Gobiernos dictatoriales que asolaron la región entre las décadas de los sesenta y los ochenta.

Desde entonces, la búsqueda, identificación y gestión de estos documentos ha tenido avances y retrocesos. En la mayoría de los países, fueron los organismos de derechos humanos y los sobrevivientes los que reconstruyeron lo ocurrido a partir de los testimonios y los documentos recopilados como parte de su resistencia a las dictaduras. En ese contexto, fueron pocas las ocasiones en las que documentos generados por los propios represores se hallaron y sirvieron para la construcción de una verdad histórica. En la mayoría de los casos, la actuación de la violencia estatal y paraestatal se constituyó como un "pacto de silencio" mantenido por los miembros de las Fuerzas Armadas y de Seguridad, frente a las demandas de verdad de los organismos de derechos humanos, el Estado y la sociedad en su conjunto (Feld y Salvi, 2016).

En Argentina, ya desde la publicación de su informe Nunca más, la Comisión Nacional sobre la Desaparición de Personas (Conadep, 1984) se refirió a la existencia de un "cúmulo importante de documentación que se ha destruido o que se mantiene oculta por los autores del accionar represivo" (p. 204). Las Fuerzas Armadas declararon en ese entonces, y durante los años siguientes, que la documentación no existía o había sido destruida. El sostenimiento de esa negativa implicó que, a lo largo de varias décadas, tanto la reconstrucción histórica como el juzgamiento penal de los responsables estuvieran sostenidos mayormente sobre los testimonios de las víctimas.

En ese contexto, en 2006 el gobierno del entonces presidente Néstor Kirchner dispuso por primera vez la "apertura y el acceso" a los archivos de las Fuerzas Armadas para la "obtención de elementos" que pudieran estar asociados a violaciones de los derechos humanos durante la última 
dictadura militar (1976-1983). El objetivo de dicha "apertura" fue brindar documentación a los juicios por crímenes de lesa humanidad que habían sido recientemente reabiertos ${ }^{1}$. Al principio ello significó facultar a la Dirección de Derechos Humanos del Ministerio de Defensa para acceder a los archivos del Estado Mayor Conjunto de las Fuerzas Armadas (EMCO), de los Estados Mayores Generales del Ejército, la Armada y la Fuerza Aérea y del para entonces extinto Consejo Supremo de las Fuerzas Armadas. La resolución levantó el secreto militar y ordenaba que la documentación debía ser remitida al Archivo Nacional de la Memoria, según lo preveía el decreto de creación de este último en $2003^{2}$.

Sin embargo, el impacto de esta decisión estuvo lejos de ser inmediato. El interés de este artículo es estudiar dicho proceso, haciendo especial hincapié en las estrategias que, desde el Ministerio de Defensa, se utilizaron para responder a la demanda social por la "apertura de los archivos militares" y especialmente para traspasar la documentación a la esfera judicial. En tal sentido, este análisis continúa una investigación iniciada antes (Balé, 2018), cuyo objetivo era comprender el proceso de "apertura de los archivos" en tanto "política de memoria". Aquí el interés consiste en relevar específicamente la dinámica interna del proceso, para dar cuenta de las disputas y modalidades que se pusieron en juego a la hora de acceder, organizar y analizar los diferentes acervos. De este modo, se pretende contribuir en la reflexión sobre qué lecciones es posible extraer de este proceso para la apertura de otros archivos en Argentina y en otros países de Latinoamérica.

\footnotetext{
${ }^{1}$ La Ley 25.779, sancionada por el Congreso Nacional en agosto de 2003, declaró la nulidad de las leyes de Obediencia Debida y Punto Final. En junio de 2005, la Corte Suprema de Justicia declaró la invalidez e inconstitucionalidad de ambas leyes y reafirmó la imprescriptibilidad de los delitos de lesa humanidad, abriendo el camino para la reapertura de los juicios.

${ }_{2}^{2}$ Como se verá, la mecánica de implementación fue finalmente diferente y la mayor parte del relevamiento se realizó directamente en los archivos militares.
}

Hallazgos

ISSN: 1794-3841 | e-ISSN: 2422-409X | DOI: https://doi.org/10.15332/2422409X 
Con estos propósitos, se examina la labor de los Equipos de Relevamiento y Análisis Documental de los Archivos de las Fuerzas Armadas que fueron creados en 2010 por la Dirección de Derechos Humanos y Derecho Internacional Humanitario del Ministerio de Defensa. Estos equipos estuvieron conformados por investigadores civiles que tuvieron a su cargo el relevamiento de los archivos dentro de las dependencias militares. El corpus de esta indagación se compone de nueve entrevistas en profundidad (dos de carácter colectivo y el resto individuales) realizadas a quince miembros de estos equipos, así como a funcionarias de la Dirección de Derechos Humanos del Ministerio de Defensa e integrantes del Programa de Modernización de Archivos, creado en 20123. También se indagó mediante observación etnográfica de los seis Archivos Generales e Históricos de las Fuerzas Armadas, según la perspectiva trazada por Da Silva Catela (2007) para el "mundo de los archivos". Por último, recurrimos al análisis de la normativa pertinente y de diferentes materiales (informes de investigación, ponencias, reportes a organismos internacionales) elaborados por los equipos arriba mencionados, con el objeto de reconstruir la "política de apertura", mostrar sus límites y sus condiciones de posibilidad.

\section{Los "archivos de la represión" en el Cono Sur}

En las últimas dos décadas el interés por el uso de los archivos en el ámbito de los derechos humanos ha tenido un crecimiento exponencial (Caswell, 2014; Baumgartner et ál., 2016). Tanto en el Cono Sur como en otros países del mundo la importancia de preservar documentos de archivo para la promoción y defensa de los derechos humanos ha pasado a

\footnotetext{
${ }^{3}$ Ese año, la Dirección de Derechos Humanos creó el Programa de Modernización de Archivos del Ministerio de Defensa, que tuvo por función normalizar los criterios y pautas de gestión archivística en los seis archivos militares. Para un análisis de su tarea, véase Balé (2018).
}

Hallazgos

ISSN: 1794-3841 | e-ISSN: 2422-409X | DOI: https://doi.org/10.15332/2422409X 
ser un problema común, hasta el punto de configurarse un "imperativo archivístico" (Bickford, 2000). En términos cronológicos, podría decirse que el entrecruzamiento de archivos y derechos humanos adquirió relevancia internacional por primera vez mediante el informe de la Organización de las Naciones Unidas para la Educación, la Ciencia y la Cultura (Unesco) y el Consejo Internacional de Archivos sobre "gestión de los archivos de servicios de seguridad del Estado de los desaparecidos regímenes represivos", de 1995. Se trata de un estudio que contiene un conjunto de casos paradigmáticos, y ofrecía una propuesta de código deontológico para el tratamiento de documentación. Desde esa perspectiva, inauguraba una línea de reflexión orientada a la preservación de los documentos producidos por regímenes represivos, que fueron considerados esenciales para los procesos de democratización. Entre otros aspectos, ello supone habilitar y dar cuenta de su efecto boomerang, según el cual, una vez que los procesos represivos han finalizado, los documentos sirven para una función social diametralmente opuesta a la que tuvieron en su origen (González, 2009).

En paralelo con esto, dentro de las ciencias sociales diversos trabajos se han dedicado a plantear las características que supone el tratamiento de "archivos de la represión" en América Latina, y estos comprenden no solo los archivos de las instituciones represivas, sino también aquellos que estén vinculados a violaciones a los derechos humanos, cualquiera sea su origen. Así, en un volumen pionero sobre la temática, Jelin (2002) consideraba estos archivos como escenarios de las luchas por las memorias individuales y públicas. En el mismo sentido, Da Silva Catela (2002) introdujo la comprensión de los archivos como "territorios de memoria", es decir, como "espacios dinámicos en los cuales los diferentes actores involucrados desarrollaron estrategias de encuadramiento, conquista y 
disputa por la 'soberanía' de los documentos, entendidos como una metonimia del control sobre el pasado" (Da Silva Catela, 2002, p. 22). Desde esta perspectiva, diversos autores han abordado la apertura de archivos en el Cono Sur, especialmente los "Archivos del Terror" de la dictadura paraguaya (Vélez Jiménez, 2013), los archivos secretos de la policía brasileña (Fico, 2009), así como archivos de organizaciones no gubernamentales (Bickford, 2000), como el Comité para la Defensa de los Derechos Humanos para los países del Cono Sur (CLAMOR) y el archivo chileno de la Vicaría de la Solidaridad (Cruz, 2002). Para el caso uruguayo, Markarian (2016) ha trabajado sobre las condiciones de accesibilidad de un conjunto de archivos que fueron recientemente abiertos: el archivo del Ministerio de Relaciones Exteriores, de la Dirección Nacional de Información e Inteligencia y el archivo "Berruti", hallado en una dependencia del Ministerio de Defensa en 2006. A diferencia de lo que - como veremos - ha sucedido en Argentina con los archivos militares, estos dos últimos acervos fueron puestos bajo la órbita civil, aunque persisten dificultades y polémicas en torno a sus condiciones de preservación y acceso público (Markarian, 2016; Rico, 2016; Caetano, 2011).

En Argentina, la producción académica en torno a los "archivos de la represión" también ha crecido significativamente conforme se fueron encontrando o configurando nuevos acervos. Uno de los casos con mayor trascendencia ha sido el hallazgo del archivo de la Dirección de Inteligencia de la Policía de la Provincia de Buenos Aires (DIPPBA). Este fue desclasificado en 2000 y entregado en custodia a la Comisión Provincial por la Memoria de la Provincia de Buenos Aires. Entre otras cuestiones, se han analizado las tensiones y debates suscitados tras su apertura al público, así como sus posibles usos historiográficos y memoriales (Kahan, 2007; Flier, 2006; Funes, 2006). 
Así mismo, se han explorado los usos y las particularidades de un conjunto de archivos más pequeños que fueron desclasificados entre 2002 y 2007 y que corresponden en su mayoría a fuerzas policiales provinciales (Da Silva Catela, 2007). A diferencia de lo que ha ocurrido en otros países (por ejemplo, Brasil), una característica recurrente del caso argentino ha sido la creación paralela de instituciones que custodian estos archivos, ya sea comisiones provinciales por la memoria (como el caso citado de la DIPPBA), archivos provinciales, museos de la memoria y, finalmente, el Archivo Nacional de la Memoria, que fue creado en 2003 (Da Silva Catela, 2007; Nazar, 2018). Como señalan varios especialistas, esta segmentación se debe en parte a la ausencia de un sistema nacional de archivos que tenga en cuenta la gestión del patrimonio documental del Estado argentino de manera integral. Consecuentemente, una de las mayores dificultades en relación con el acceso a archivos vinculados a graves violaciones a los derechos humanos es su fragmentación y dispersión actuales.

En este contexto, los archivos de las Fuerzas Armadas emergen como un caso de estudio particular. Durante décadas, los departamentos o servicios históricos de cada una de las Fuerzas, y en especial los archivos generales, estuvieron sujetos a una marginalización de sus funciones, y han abonado un sentido común que los considera meros depósitos, tanto dentro como fuera de la corporación militar (Alves, 2017). A excepción de algunos pocos trabajos de los propios miembros de los Equipos de Relevamiento (Lavintman et ál., 2017; Lettieri y Agostini, 2019), su proceso de "apertura" ha sido poco indagado. Este artículo se propone aportar a este conocimiento, mostrando las diferentes estrategias que se construyeron desde el Ministerio de Defensa para intervenir sobre los archivos militares directamente donde estos se encontraban, según una trayectoria que los 
convirtió de meros depósitos en "territorios de memoria" sujetos a control civil.

\section{La disputa por el control civil de los archivos militares}

El proceso de "apertura" de los archivos militares encuentra uno de sus hitos un día antes de conmemorarse el trigésimo aniversario del golpe de Estado de 1976, cuando, según consignaban los principales diarios del país, el entonces presidente Néstor Kirchner "ordenó abrir los archivos militares de la dictadura” " El gobierno ordenó abrir los archivos militares de la dictadura”, 2006; "Ordenan la apertura de los archivos militares”, 2006). Este avance se inscribía en una serie de gestos que Kirchner había promovido en materia de políticas de memoria, así como en la articulación que progresivamente fue construyendo con importantes sectores del movimiento de derechos humanos (Barros y Morales, 2017). Dicha articulación se basó en la adopción de un conjunto de políticas públicas que respondían a demandas concretas del movimiento, dentro de las cuales la más importante fue el impulso del Ejecutivo a la reapertura de las causas por crímenes de lesa humanidad. Asimismo, el acercamiento entre Kirchner y los organismos de derechos humanos se sostuvo en un nuevo paradigma discursivo en torno al pasado, que incluía su propio posicionamiento como "militante setentista" (Montero, 2012). En este sentido, aunque desde la transición a la democracia los diferentes gobiernos y niveles estatales desarrollaron políticas de memoria heterogéneas -e incluso contradictorias - (Alonso, 2011), numerosos especialistas coinciden en que la intervención del gobierno de Kirchner significó un punto de clivaje (Carnovale, 2006; Lvovich y Bisquert, 2008). Aquella formulación según la cual se abrían los "archivos de la dictadura" fue reproducida por distintos medios de comunicación y se hacía eco de dos confusiones: el titular daba la impresión de que la dictadura militar 
(1976-1983) había producido sus propios archivos de manera separada y que eran estos los que se abrían por primera vez, o bien, a la inversa, que los archivos militares cuya apertura se anunciaba poseían exclusivamente documentos referidos al último periodo dictatorial. Ninguna de las dos opciones era precisa, ya que los archivos poseían documentación de carácter administrativo, y como se verificó después, en su mayoría no contenían información explícita acerca de las víctimas de la represión. Además, si bien existían documentos que habían sido producidos durante la represión militar (o se referían a ella) y que probaron ser de valor para su reconstrucción histórica o judicial, la mayor parte de los acervos contenidos en los archivos de las Fuerzas Armadas databan de otros periodos. Por otro lado, aunque las noticias recogían adecuadamente la negativa sistemática que las Fuerzas Armadas habían dado al acceso a cualquier documento referido a la represión ilegal, la idea de "apertura" debía ser matizada, ya que, de acuerdo con la decisión inicial de Kirchner, no se trataba de otorgar acceso público a los documentos, sino de habilitar el acceso para su uso judicial.

En este escenario, la expectativa por parte de los organismos de derechos humanos era que la posibilidad de acceder a los archivos podía ser útil para ratificar por medio de documentos escritos la operatoria represiva que los sobrevivientes y otros testigos habían estado describiendo oralmente durante décadas. Más aún, el diario Página 12 afirmaba que la apertura de los archivos era "un reclamo histórico de los organismos de derechos humanos, que suponen que allí está contenida la información para saber qué pasó con los 30 mil desaparecidos" (“Ordenan la apertura de los archivos militares”, 2006). Por otro lado, el diario Clarín refería que, dentro del ámbito castrense, la "apertura" era percibida como un gesto meramente simbólico que no iba a arrojar resultados relevantes ("El gobierno ordenó abrir los archivos militares de la dictadura”, 2006). 
Teniendo en cuenta esta disparidad: ¿qué esperaban encontrar en aquellos archivos los funcionarios del Ministerio de Defensa que impulsaron su "apertura"?

Dado el carácter clandestino de las acciones represivas, una hipótesis posible era que no hubiera quedado registro de ellas. Sin embargo, como ha sido señalado por diferentes autores, la práctica represiva respondió a una cadena de mando que, a su vez, dependió de instancias institucionales y administrativas que, por su naturaleza burocrática, sí debían guardar registros (Águila, 2015). En ese sentido, la Dirección Nacional de Derechos Humanos y Derecho Internacional Humanitario, encargada de supervisar las respuestas a los oficios judiciales (es decir, a los pedidos de documentación formulados por tribunales y fiscalías), apostó no tanto a hallar documentación producida con fines exclusivamente represivos, sino a encontrar aquella que, habiendo sido elaborada para otros fines, pudiera aportar información sobre aquellos. En ese sentido, Natalia Federman (exdirectora de Programas de la Dirección de Derechos Humanos del Ministerio de Defensa entre 2006 y 2010) recuerda como puntapié inicial el caso del exteniente coronel Bruno Laborda, quien en un reclamo administrativo de 2004 relataba los crímenes que "la oficialidad superior le ordenó hacer cuando era subteniente y teniente”, durante la dictadura.

Laborda se proponía apelar la decisión de la Junta Superior de Calificaciones de Oficiales que le había rechazado su ascenso a coronel, para lo cual, en una carta dirigida al Jefe General del Ejército, "confesaba" de manera pormenorizada los crímenes de cinco militantes, una de ellas embarazada ${ }^{4}$. Para los funcionarios de la Dirección, el caso Laborda evidenció que aun si las Fuerzas Armadas no habían elaborado registros

\footnotetext{
${ }^{4}$ El entonces Jefe del Ejército, Roberto Bendini, le negó el ascenso y presentó la carta a la justicia que la evaluó como prueba. Laborda murió mientras estaba siendo enjuiciado en la megacausa La Perla (Barrera, 2013).
}

Hallazgos

ISSN: 1794-3841 | e-ISSN: 2422-409X | DOI: https://doi.org/10.15332/2422409X 
explícitos de la represión ilegal mientras la cometían (o si tales registros no se conservaban), era necesario relevar la totalidad de los archivos, porque incluso documentos producidos muchos años después podían contener información sobre la comisión de delitos y sus perpetradores.

Paralelamente, el episodio dio cuenta de que hasta la intervención del Ministerio de Defensa, los archivos militares no aparecían dentro de las Fuerzas Armadas como una cuestión relevante y no eran considerados un territorio en disputa.

Ahora bien, pese a lo anunciado, la reticencia de la corporación militar, así como la prolongada falta de una política integral de preservación del patrimonio documental, convirtieron la "apertura" en un proceso arduo y complejo. En efecto, hasta la intervención del Ministerio de Defensa, con la creación de los Equipos de Relevamiento y Análisis Documental en 2010 y, luego, del Programa de Modernización de Archivos (PMA), creado en 2012, los archivos de las Fuerzas Armadas funcionaban como meros depósitos de documentación y presentaban grandes restricciones de accesibilidad (Nazar, 2007, p. 420).

Por esa razón, y considerando las demoras y evasivas en la contestación de los oficios judiciales, en los años siguientes la Dirección se propuso desarrollar una estrategia diferente que permitiera salvar las distintas restricciones: las prácticas (asociadas al estado precario de los fondos), las simbólicas (que se vinculaban con el desconocimiento respecto de los tipos documentales producidos por la institución) y las que se pueden denominar "ideológicas" o de disputa por el control de los archivos.

De acuerdo con Federman, teniendo en cuenta la existencia de una "voluntad política" que emanaba del poder ejecutivo para sostener el avance de los juicios por crímenes de lesa humanidad, en 2010 la Dirección se propuso crear un grupo de trabajo propio para que emprendiera "la tarea de relevamiento y análisis de toda la documentación 
que pueda resultar de valor histórico y/o judicial que se encuentre archivada y/o custodiada” (Ministerio de Defensa, 2010). De este modo, fueron creados los Equipos de Relevamiento y Análisis Documental que estuvieron integrados por investigadores e investigadoras civiles que, por primera vez, estuvieron facultados a "acceder de manera irrestricta" a la documentación.

Esta estrategia tuvo como condición de posibilidad el desarrollo de una política de Estado - sostenida por los Gobiernos de Néstor Kirchner (2003-2007) y Cristina Fernández (2007-2015) - que se propuso avanzar en el proceso de control civil del área de la defensa. Ello implicaba comenzar a revertir una tendencia histórica según la cual el Ministerio de Defensa constituía un espacio "colonizado" por las Fuerzas Armadas y era considerado su "propiedad" (Canelo, 2012) ${ }^{5}$. A su vez, esta decisión se inscribía en un cambio de posición del entonces Gobierno de Kirchner en torno a cómo lidiar con el pasado reciente, según se mencionó más arriba. La subordinación política de las Fuerzas Armadas y el cambio de gestualidad respecto del pasado quedaron inscritas en la memoria colectiva a partir de un conjunto de escenas emblemáticas como la decisión de conmemorar el aniversario del Golpe de Estado en el Colegio Militar de la Nación y también el gesto de Kirchner de ordenar al entonces jefe del Ejército que retirara los retratos de los generales Videla y Bignone que permanecían colgados allí (Lvovich y Bisquert, 2008).

Así mismo, la estrategia de creación de los Equipos de Relevamiento se apoyó en la desclasificación de toda la documentación relativa al periodo 1976-1983 ${ }^{6}$. Aunque era una herramienta ad hoc (es decir, no establecía

\footnotetext{
${ }^{5}$ La disputa por la conducción civil de las Fuerzas Armadas constituye un proceso que se enmarca en la incorporación de las Fuerzas Armadas al orden democrático. Al respecto, y para una evaluación de la gestión de Nilda Garré (2005-2010) como Ministra de Defensa en ese contexto, véanse Frederic (2013) y Muzzopappa (2018). ${ }^{6}$ El Decreto 4/2010 desclasificó "toda aquella información y documentación vinculada con el accionar de las Fuerzas Armadas durante el periodo comprendido entre los años
} 
mecanismos integrales de desclasificación), esta decisión permitió relevar el carácter "secreto" de la documentación, lo cual representaba uno de los principales obstáculos normativos habitualmente esgrimidos desde la corporación militar?

En consecuencia, como se ha señalado en un trabajo anterior (Balé, 2018), la creación de los Equipos de Relevamiento y Análisis modificó las relaciones de fuerza dentro de los archivos e implicó intervenir en un territorio que, hasta el momento, las Fuerzas Armadas consideraban de su exclusiva propiedad. Desde ese punto de vista, los archivos de las Fuerzas Armadas se reconfiguraron como "territorios de memoria" (Da Silva Catela, 2002), es decir, como espacios dinámicos en los cuales los diferentes actores involucrados desarrollaron estrategias de encuadramiento, conquista y disputa por la "soberanía" de los documentos, entendidos como una metonimia del control sobre el pasado (p. 22). A continuación, se exponen con más detalle las estrategias que los integrantes de los Equipos de Relevamiento pusieron en juego para disputar ese territorio, reconfigurar estos acervos y responder a las expectativas sociales que la "apertura" de los archivos traía aparejada.

\section{Activismo, producción de saberes especializados y traspaso de la documentación a la esfera judicial}

Para comprender de manera más específica el trabajo de los Equipos de

Relevamiento, es necesario considerar que las modalidades de trabajo se

1976 y 1983, así como a toda otra información o documentación, producida en otro periodo, relacionada con ese accionar".

7 A lo largo del periodo analizado, los Equipos de Relevamiento trabajaron junto con el Programa de Modernización de Archivos en proyectos específicos de desclasificación documental que incluyeron la documentación relativa al conflicto bélico en las Islas Malvinas Georgias del Sur y Sandwich del Sur (desclasificada por Decreto 503/2015), así como el "Fondo Junta Militar" que fue hallado en 2013 y que contenía, entre otros elementos, las actas secretas de las reuniones de la Junta entre 1976 y 1983. Para un análisis de esto último, véase Balé (2018).

Hallazgos

ISSN: 1794-3841 | e-ISSN: 2422-409X | DOI: https://doi.org/10.15332/2422409X

Vol. 18 N.o 36| julio-diciembre del 2021 
fueron modificando a lo largo del tiempo. Según señalan las personas entrevistadas, inicialmente la tarea de estos equipos fue entrar a los archivos y "ver qué había” (Entrevista Equipo Ejército, 12 de mayo de 2017), teniendo en cuenta la falta de instrumentos de descripción adecuados y el estado precario de los fondos. Sin embargo, no se trató de una tarea sencilla: “¿cómo encontrar aquello que no sabemos cómo está registrado ni dónde?” (Federman, 2015, p. 103).

De acuerdo con lo que se ha logrado reconstruir (Balé, 2018), el proceso estuvo signado por dos etapas. Por un lado, encontrar documentación que tuviera relevancia judicial implicó restituir la lógica de funcionamiento del archivo como un todo, es decir, requirió, por parte de los investigadores tanto hombres como mujeres-, comprender el "punto de vista nativo" (Muzzopappa, 2018) con el cual esa documentación se había producido, seleccionado y acumulado. Por ello, en una primera etapa, los Equipos de Relevamiento trabajaron en la identificación de los tipos documentales existentes y en clarificar el tipo de información que cada uno de estos podía brindar a los juicios en curso, sin contar con asistencia del personal militar. Como parte de esta tarea, en ocasiones se hallaron algunos documentos que referían de modo explícito a la comisión de delitos y que fueron utilizados para perseguir penalmente a los responsables (entrevista a un integrante del Equipo Ejército, 26 de mayo de 2017).

En este marco, los equipos redactaron el "Instructivo para la consulta de los acervos documentales de las Fuerzas Armadas", cuyo principal destinatario eran los operadores judiciales. Dicho instructivo se proponía salvar las restricciones simbólicas de acceso y describir qué tipo documentos podían ser útiles para reconstruir "el desempeño operativo de cada una de las Fuerzas en la denominada 'lucha contra la subversión”" (Ministerio de Defensa, 2010, p. 80). 
En un segundo momento, y para que el trabajo de estos equipos avanzara más allá del carácter manifiesto de los documentos, fue necesaria la construcción de un saber especializado que, al comprender el archivo como un todo, diera cuenta del conjunto de relaciones sociales que expresaba. Así, en una segunda etapa (especialmente durante la gestión de Stella Segado como directora de la Dirección de Derechos Humanos) la tarea estuvo signada por un cruce documental cuyo objetivo era no solo contextualizar los datos encontrados (por ejemplo, en relación con la estructura jerárquica en la que se inscribían), sino también trazar conexiones que no estuvieran contenidas en los documentos tomados individualmente.

Esta segunda lógica implicaba considerar el archivo como un "artefacto cultural" en el que cada pieza remitía a un universo de referencia mayor (Muzzopappa, 2018). Así, desde 2010 en adelante, estos equipos se abocaron no tanto a remitir y relevar documentación específica, sino a producir informes que contextualizaban y cruzaban documentación y que eran remitidos a demanda del poder judicial. Entre 2010 y 2015, los equipos produjeron alrededor de sesenta informes que fueron entregados a fiscalías y juzgados (entrevista a la exdirectora Nacional de Derechos Humanos, Ministerio de Defensa, 19 de septiembre de 2017). A la hora de explicar la mecánica de trabajo, señalan Lavintman et ál. (2017), integrantes del Equipo Ejército, lo siguiente: "Respecto a qué datos se pueden recabar en los archivos, despejaremos el siguiente supuesto común: no obran en dichos fondos documentales fichas de entrada a Centros Clandestinos de Detención (CCD) ni información específica sobre detenidos/as desaparecidos/as" (p. 8).

Sin embargo, señalan estos mismos investigadores: 
A través del uso de diferentes tipos documentales producidos por la misma fuerza, reconstruimos la operatoria represiva y sus registros, que se presentan de modo fragmentado. En los casos en que la justicia requiere la reconstrucción del accionar de la fuerza se enmarca en un recorte temporal y territorial (Zona, Subzona, Área). A partir de un relevamiento integral de la documentación referida a las unidades pertinentes se sistematizan los datos en un informe que 'traduce' lo encontrado en los documentos en un corpus expositivo, para ser utilizado como insumo por las fiscalías en la reconstrucción de los hechos. (Lavintman et ál., 2017, p. 8)

Este señalamiento da cuenta de la existencia de un "supuesto común" o, en otros términos, una demanda social que debieron enfrentar los investigadores en relación con aquello que se esperaba del contenido de los archivos. En efecto, como se vio al inicio, la expectativa en relación con estos acervos estaba signada por la prolongada e infructuosa búsqueda de documentos oficiales que dieran cuenta del actuar represivo ilegal y, especialmente, del destino de las personas desaparecidas. El hecho de que gran parte de la documentación hallada respondiera a la gestión cotidiana de las Fuerzas Armadas en un periodo que va más allá de la dictadura militar, o lo que es lo mismo que los archivos de las Fuerzas Armadas no fueran "archivos de víctimas” generó que quienes integraban los Equipos elaboraran otras estrategias para, como ellos mismos dicen, "cumplir con las mismas expectativas" (entrevista al Equipo Armada, 12 de junio de 2017). Así, puede decirse que la generación de informes que reconstruyeran estructuras represivas fue el modo particular en que desde la Dirección se respondió a la demanda de "apertura de los archivos" entendida no como una política archivística per se, sino como sinónimo de obtención de "verdad” e incluso de "prueba jurídica”. 
$\mathrm{Al}$ respecto, es interesante considerar el trabajo realizado por el Equipo Armada para el tercer tramo de la "megacausa ESMA", en el que se juzgaron los crímenes cometidos en el Centro Clandestino de Detención y Exterminio que funcionó en la Escuela de Mecánica de la Armada ${ }^{8}$. En el transcurso de este "megajuicio" fueron investigados los delitos de lesa humanidad cometidos contra 789 personas y 54 imputados fueron sentenciados. Según señalan las integrantes de este equipo, "el volumen de documentos utilizado y, sobre todo, el lugar de prueba fundamental en que los fiscales colocaron estos documentos han transformado a estos alegatos en un hito para la archivística" (Lettieri y Agostini, 2018, p. 8). En efecto, tras varias décadas de apoyarse en los testimonios orales de víctimas y testigos, la apertura y desclasificación de los documentos de archivo permitió por primera vez a los fiscales articular ambas instancias para reconstruir lo sucedido en sede judicial (Dandan, 2017).

El Equipo Armada preparó dos informes que fueron incorporados al expediente judicial con documentos anexos digitalizados. El primer informe aportó a la reconstrucción de las estructuras orgánicas de la ESMA en los años de su funcionamiento como Centro Clandestino, así como el relevamiento de actuaciones y legajos de personal que fuera destinado allí. Dicha reconstrucción fue posible gracias a una revisión exhaustiva de los listados de pagos que asentaban el "destino, matrícula, nombre, grado y monto que recibía cada oficial, suboficial, conscripto y aspirante naval" (Lettieri y Agostini, 2018, p. 5). El segundo informe fue utilizado para el juzgamiento del tramo referido a la "aviación naval", es decir, aquel en el que se juzgaba a los pilotos acusados de participar en los denominados "vuelos de la muerte". Aunque su existencia ya había sido

\footnotetext{
${ }^{8}$ La Escuela de Mecánica de la Armada (ESMA) fue uno de los centros clandestinos de detención más conocidos de los más de seiscientos que fueron instaurados durante el terrorismo de Estado a lo largo del país. Se calcula que por allí pasaron alrededor de cinco mil personas y solo un centenar sobrevivió.
}

Hallazgos

ISSN: 1794-3841 | e-ISSN: 2422-409X | DOI: https://doi.org/10.15332/2422409X 
probada anteriormente con base en testimonios, investigaciones periodísticas e incluso confesiones de perpetradores ${ }^{9}$, la particularidad de este caso es que el aporte documental permitió por primera vez reconstruir la mecánica por medio de la cual la Armada movilizaba los aviones que se utilizaban para los "vuelos". A partir del uso de documentos de carácter público como reglamentos, boletines y manuales, la fiscalía pudo reconstruir la operatoria de los "vuelos de la muerte" y evidenciar cómo se constituía la cadena de responsabilidades (Dandan, 2017). Al respecto, las integrantes del Equipo Armada señalan:

¿Cómo podíamos aportar a través de un archivo administrativo con los vuelos de la muerte? Ese era el pedido que nos hacía el tribunal. Y en relación a eso nosotros elegimos una vía que fue presentar toda la documentación que teníamos sobre aviación naval en ese momento. Y estamos hablando de reglamentos públicos, después de 35, 40 años, tomar un reglamento público era una decisión porque vos decís, ya pueden haber circulado en todos los juicios, los pueden tener, digamos, pero nuestra función desde el archivo era presentar los documentos con los que contábamos, entonces realizamos un informe que estaba basado en tipos documentales que no solíamos utilizar: reglamentos, publicaciones, manuales, boletines. $Y$ eso lo completamos con los legajos de algunas cuadrillas que relevamos. Y el resultado fue súper positivo de parte de la Fiscalía. (Entrevista al Equipo Armada, 12 de junio de 2017)

El hecho de que los documentos fueran en su mayoría públicos - es decir, no estaban sometidos a ninguna clasificación de seguridad - es un punto por subrayar, ya que evidencia los múltiples niveles de acceso comprometidos en los procesos de "apertura" de los archivos.

\footnotetext{
${ }^{9}$ El ejemplo paradigmático es la confesión del excapitán de corbeta Adolfo Scilingo, en entrevista con el periodista Horacio Verbitsky en marzo de 1995.
}

Hallazgos

ISSN: 1794-3841 | e-ISSN: 2422-409X | DOI: https://doi.org/10.15332/2422409X 
Específicamente queda en evidencia que la demanda social de "apertura" no refiere solo a desbloquear el acceso en términos normativos, sino a que los documentos producidos por las instituciones represivas puedan ser reutilizados y reorientados a la búsqueda de memoria, verdad y justicia.

En esa misma línea, la entrada y puesta en funcionamiento de los Equipos de Relevamiento muestra que la "activación" (Ketelaar, 2001) de esos documentos, antes invisibles, se inscribe en un estado específico de la memoria social y del conocimiento histórico en torno al funcionamiento del plan represivo. Este conocimiento, producido por los organismos de derechos humanos y también en sede judicial, implicó destacar la dimensión institucional de lo que las Fuerzas Armadas denominaron "lucha contra la subversión". En ese sentido, el proceso por el cual los archivos burocrático-administrativos pudieron aportar información que contribuyera al desarrollo de los juicios por crímenes de lesa humanidad supone comprender que el actuar de estas fuerzas no se reducía a un conjunto de responsabilidades aisladas. Por el contrario, la idea de que el análisis y el relevamiento de documentos administrativos podían proveer información a la hora de reconstruir el entramado represivo partía de entender que dicho entramado se ligaba de manera orgánica y funcional a la normalidad de las actividades de las Fuerzas Armadas en el periodo, a la vez que contribuyó a ratificar esa idea ${ }^{10}$. De esta manera, ello evidencia un vínculo fuerte entre memoria social y modos de configuración del archivo, que si bien no es exclusivo del tipo de archivos analizados, se vuelve aquí particularmente evidente.

\footnotetext{
${ }^{10}$ Esto no significa, al mismo tiempo, que los documentos conservados en los archivos de las Fuerzas Armadas deban ser tenidos como "verdades absolutas". Tal suposición caería en la paradoja de tomar como "más verdadera" la palabra de los perpetradores, que no solo está sujeta a sus propias lógicas de funcionamiento (por ejemplo, el sistema de ascensos de grado en cada una de las fuerzas), sino que además se presenta como éticamente cuestionada.
}

Hallazgos

ISSN: 1794-3841 | e-ISSN: 2422-409X | DOI: https://doi.org/10.15332/2422409X 
Por último, una cuestión clave a la hora de considerar esta nueva configuración del archivo se relaciona con la progresiva consolidación del vínculo entre la formulación de un saber especializado y el activismo de los investigadores jóvenes que integraron los Equipos de Relevamiento a lo largo del periodo analizado. Gracias al trabajo de campo se ha logrado constatar la participación de veintisiete investigadores (trece mujeres y catorce varones). Inicialmente, ninguna de estas personas tenía formación específica en archivística (lo cual se explica por la falta de espacios de formación en el país), sino que la fueron adquiriendo en el transcurso del propio desempeño, tanto mediante las capacitaciones que se llevaban a cabo desde el Archivo General de la Nación como a partir de iniciativas personales.

Algunas contaban con una trayectoria de activismo en organismos de derechos humanos u otros espacios políticos. Por lo general, su vinculación laboral en los Equipos de Relevamiento se producía por recomendación de otros miembros o de la propia Dirección, de modo que el trabajo se sustentaba, a la vez, sobre un "tejido de relaciones preexistentes" (Balé, 2018) que se percibía indispensable para desarrollar la tarea en el marco de un territorio de disputas como el descrito arriba. A ello deben sumarse condiciones laborales precarias (con contratos temporales) que dependían para su renovación de las partidas presupuestarias que provenían de fondos del Programa de Naciones Unidas para el Desarrollo (PNUD).

Estas cuestiones son significativas en la medida en que evidencian la existencia de una ética del compromiso militante que sustentaba la tarea cotidiana. En ese sentido, a lo largo del desarrollo de la política se fue produciendo una asociación entre una incipiente expertise y una forma del activismo que resultó central para “abrir” los archivos en sus múltiples niveles. Esto incluyó mejorar las condiciones prácticas de acceso y 
conservación, modificar su status dentro de las Fuerzas Armadas y, por supuesto, traspasar la documentación hallada a la esfera judicial. De este modo, es notable que los archivos emergieron para estos investigadores como un espacio de activismo en el marco del cual se desarrollaba un compromiso con la causa de los derechos humanos y también como un destino profesional y laboral posible. Esto es especialmente cierto para quienes permanecieron en la Dirección por varios años, ocupando diferentes posiciones e incluso trabajando luego en otros archivos o dependencias de la administración pública nacional.

Esta combinación de activismo con producción de saberes específicos resulta clave a la hora de explicar la productividad que alcanzaron los archivos militares en el periodo analizado. Si bien tenía como condición necesaria la decisión política de intervenir sobre estos, la trayectoria y activación de los documentos no emanaba directamente de la voluntad presidencial, sino que fue el producto de las capacidades introducidas por estos investigadores, cuyo papel no estaba previsto y, sin embargo, resultó crucial en el progresivo desarrollo de la política.

\section{Conclusiones}

Como afirma Rico (2016), si en los inicios del milenio cabía preguntarse por la existencia de archivos estatales que guardaran información sobre las dictaduras del Cono Sur, en la actualidad esa cuestión se ha respondido afirmativamente. El problema que hoy atraviesa tanto el campo de la archivística como el de los derechos humanos es cómo sistematizar los archivos que fueron hallados, cómo organizar y preservar la documentación y, por último, cómo garantizar su acceso más allá de los vaivenes políticos en los diferentes países (Markarian, 2016; Barahona Garrido y Herlitz Cifuentes, 2017; Nazar, 2018). 
Teniendo en cuenta esto, el proceso de "apertura" de los archivos de las Fuerzas Armadas argentinas ha manifestado avances y limitaciones. Por un lado, el análisis propuesto en este artículo ha mostrado cómo las agencias estatales argentinas fueron progresivamente metabolizando la demanda social por la "apertura de los archivos" - vigente desde la transición a la democracia- por medio de la implementación de estrategias que les permitieran intervenir sobre los archivos militares. En ese sentido, se ha analizado el trabajo de los Equipos de Relevamiento y Análisis y su ingreso a los archivos como una puesta en cuestión de la autonomía de las Fuerzas Armadas, según una trayectoria que convirtió a los archivos de "depósitos de documentación" en "territorios de memoria". En esa línea, se han estudiado las estrategias de los Equipos de Relevamiento para dotar de valor los documentos de archivo y otorgarles nuevos usos, específicamente a la hora de transferirlos a la esfera judicial. Hubo una atención especial en lo que se consideró la producción de un saber especializado, que, al comprender el archivo como un todo, logró reconvertir la documentación administrativa en una fuente valiosa para la reconstrucción de las estructuras represivas vigentes durante el terrorismo de Estado.

Al mismo tiempo, se vio cómo la expectativa social articulada en torno a estos archivos, así como el estado de la memoria social, tuvieron una fuerte influencia en las maneras en que se moduló esta tarea. En ese sentido, aun si los archivos que habían sido abiertos no eran, como indicaban los medios de comunicación, "los archivos de la dictadura", el modo en que se trabajaron, analizaron y reconfiguraron sus acervos los reconfiguró como tales e hizo posible que se convirtieran en insumos para los juicios en curso. Ese proceso deja en evidencia que el valor de los archivos producidos durante regímenes represivos, así como sus potenciales efectos y usos, no es automático (no hay, en ese sentido, una definición estable de 
qué constituye un "archivo de la represión”), sino que es construido y activado por los actores sociales que intervienen en ellos.

Por otro lado, se ha destacado como un elemento importante de este proceso el anudamiento entre el activismo en derechos humanos y la producción de saberes específicos por parte de los integrantes de los Equipos de Relevamiento. Es esta combinación la que permitió sostener el trabajo sobre los archivos en un contexto de tensión entre lo civil y lo militar, así como traspasar documentación valiosa a la esfera judicial. En consonancia con los hallazgos de otros autores para otras áreas de política pública en el mismo periodo, el Estado fue concebido por estos actores como un espacio desde el cual se tramitaban compromisos militantes (Perelmiter, 2016; Vázquez, 2014), de un modo que permitió asegurar la continuidad de la política en ausencia de un marco regulatorio integral del patrimonio documental.

Este último punto permanece como una deuda pendiente en lo que se refiere a asegurar la accesibilidad de los "archivos de la represión" de manera independiente de las voluntades políticas, a menudo cambiantes. Como lo señala Markarian para el caso uruguayo (2016), allí el relevamiento de la documentación estuvo asociado a acciones específicas de rescate para diferentes investigaciones (especialmente judiciales), pero estas acciones no se han enmarcado en una política global en materia archivística a escala nacional. Esta articulación, que debería atravesar los distintos ámbitos del Estado, constituye una demanda actual de diversos actores (organismos de derechos humanos, investigadores, archivistas y trabajadores estatales, entre otros) que entienden dicha articulación como una medida esencial para garantizar el acceso público a los documentos de archivo desde una perspectiva de derechos humanos. 


\section{Sobre la autora}

Cinthia Balé. Doctora en Ciencias Sociales (FSOC-UBA) y becaria posdoctoral del Conicet con sede en la Escuela Interdisciplinaria de Altos Estudios Sociales (Idaes-Unsam). Forma parte del Núcleo de Historia Reciente con sede en el Idaes y del grupo "Lugares, marcas y territorios de la memoria” en el marco del Núcleo de Estudios sobre Memoria (IDES). A lo largo de su investigación doctoral examinó los modos de producción de políticas públicas de memoria durante los gobiernos kirchneristas (20032015), atendiendo a sus dimensiones reparatorias, conmemorativas, archivísticas y de lugarización. Actualmente se dedica a analizar las disputas en torno al discurso de los derechos humanos y las transformaciones en los dispositivos de gestión estatal del pasado reciente en Argentina. Ha publicado Memoria e identidad durante el kirchnerismo: la "reparación" de legajos laborales de empleados estatales desaparecidos (2018) y “¿Quién tiene derecho a recordar? Las disputas por la memoria durante los gobiernos kirchneristas (Argentina, 2003-2015)” (2021), entre otros artículos en revistas especializadas.

\section{Referencias}

Águila, G. (2015). Violencia política, represión y actitudes sociales en la historia argentina reciente. Pensar con la Historia desde el siglo XXI. En P. Pereira (Ed.), Pensar con la Historia desde el siglo XXI. XII Congreso de la Asociación de Historia Contemporánea (pp. 5569-5588). Universidad Autónoma de Madrid.

Alonso, L. (2011). Vaivenes y tensiones en la institucionalización de las memorias sobre el terror de Estado. El caso de Santa Fe, Argentina, entre 1983 y la actualidad. Cuadernos de Historia. Serie Economía y Sociedad, (12), 35-70. 
Alves, E. (2017, 27 de septiembre). Impacto de las políticas de Justicia Transicional en el rol social del archivero: El caso de los Archivos Generales e Históricos de las Fuerzas Armadas y la profesionalización de su personal. Logros, límites y potencialidades (2012-2016) [ponencia]. XII Congreso de Archivología del Mercosur “Archivos y archiveros en la sociedad del conocimiento”, Universidad Nacional de Córdoba, Argentina.

Balé, C. (2018). Usos del archivo y políticas de la memoria: un análisis del proceso de "apertura" de los archivos militares en Argentina (2003-2015). Nuevo Mundo Mundos Nuevos [En línea] URL: http://journals.openedition.org/nuevomundo/73860; DOI: https://doi.org/10.4000/nuevomundo.73860

Baumgartner, E., Brandon H., Jones, B., Kelly, G. y Oliveira, I. (2016). Introduction: Documentation, Human Rights and Transitional Justice. Journal of Human Rights Practice, 8 (1), 1-5. https://doi.org/10.1093/jhuman/huwoo2

Barahona Garrido, B. y Herlitz Cifuentes, H., (2017). Archivos de la represión en Chile: entre el acceso y la desclasificación. Serie Bibliotecología y Gestión de Información, (99). http://eprints.rclis.org/31495/1/Serie\%20N\%C2\%Bo99\%203.ed..pdf

Barrera, L. (2013, 24 de julio). Murió Laborda, el represor que quería un ascenso por sus crímenes. Infojus Noticias. http://www.infojusnoticias.gov.ar/provinciales/muriolaborda-el-represor-que-queria-un-ascenso-por-sus-crimenes-327.html

Barros, M. y Morales, V. (2017). La lucha por los derechos humanos en la Argentina: redefiniciones, avances y desafíos en el nuevo milenio. A Contracorriente, 14(3), 110-136. https://acontracorriente.chass.ncsu.edu/index.php/acontracorriente/article/view/ 1589

Bickford, L. (2000). Human Rights Archives and Research on Historical Memory: Argentina, Chile, and Uruguay. Latin American Research Review, 35(2), 160-182. http://www.jstor.org/stable/2692138

Caetano, G. (2011). Los archivos represivos en los procesos de "justicia transicional": una cuestión de derechos. Perfiles Latinoamericanos, 19(37), 9-32. 
Canelo, P. (2012). 'Un ministerio de tercera línea'. Transformaciones en el reclutamiento y las trayectorias de los ministros de Defensa argentinos. PolHis, Boletín Bibliográfico Electrónico del Programa Buenos Aires de Historia Política, 5(9), 319-329. http://historiapolitica.com/datos/boletin/Polhis9_CANELO.pdf

Carnovale, V. (2006). Memorias, espacio público y Estado: la construcción del museo de la memoria. Estudios AHILA de Historia Latinoamericana, (2). http://riehr.com.ar/archivos/Investigacion/Carnovale\%20-\%20Museo\%20de\%20l a\%20ESMA.pdf

Caswell, M. (2014). Defining human rights archives: introduction to the special double issue on archives and human rights. Archival Science, 14(3-4), 207-213. https://doi.org/10.1007/s10502-014-9226-O

Comisión Nacional sobre la Desaparición de Personas [CONADEP]. (1984). Nunca Más. Informe de la Comisión Nacional sobre la Desaparición de Personas. EUDEBA.

Cruz, M. A. (2002). Silencios, contingencias y desafíos: el Archivo de la Vicaría de la Solidaridad en Chile. En L. da Silva Catela y E. Jelin (Comps.), Los archivos de la represión: documentos, memoria y verdad (pp. 137-178). Siglo XXI.

Dandan, A. (2017, 4 de diciembre). Se pensó el juicio como una acción reparatoria. Página 12. https://www.pagina12.com.ar/80273-se-penso-el-juicio-como-unaaccion-reparatoria

Da Silva Catela, L. (2007). Etnografía de los archivos de la represión en Argentina. En M. Franco, M. y F. Levin (Eds.), Historia reciente. Perspectivas y desafíos para un campo en construcción (pp. 183-220). Paidós.

Da Silva Catela, L. (2002). El mundo de los archivos. En L. da Silva Catela, L. y E. Jelin (Comps.), Los archivos de la represión: documentos, memoria y verdad (pp. 195219). Siglo XXI.

El gobierno ordenó abrir los archivos militares de la dictadura. (2006, 23 de marzo). Clarín. https://www.clarin.com/ediciones-anteriores/gobierno-ordeno-abrirarchivos-militares-dictadura o B10ei5SJAYl.html

Federman, N. (2015). La política de Archivos de las FF.AA. en el proceso de memoria, verdad y justicia. Voces en el Fénix, (48), 96-105. 
Feld, C. y Salvi, V. (2016). Presentación: Cuando los perpetradores hablan. Dilemas y tensiones en torno a una voz controvertida. Rúbrica Contemporánea, 5(9), 103122. https://doi.org/10.5565/rev/rubrica.116

Fico, C. (2009). Archivos secretos de la dictadura brasileña. En V. Markarian y I. Wschebor (Comps.), Archivos y derechos humanos. Los casos de Argentina, Brasil y Uruguay (pp. 21-34). Universidad de la República.

Flier, P. (2006). El archivo de la DIPBA: un hallazgo clave para una historia de los imaginarios represivos en Argentina. Imago Americae. Revista de estudios del imaginario, 1(1), 226-227.

Frederic, S. (2013). Las trampas del pasado: las Fuerzas Armadas y su integración al Estado democrático en Argentina. Fondo de Cultura Económica.

Funes, P. (2006). “Secretos, confidenciales y reservados”. Los registros de las dictaduras en la Argentina. El Archivo de la Dirección de Inteligencia de la Policía de la Provincia de Buenos Aires. En H. Quiroga y C. Tcach (Comps.), Argentina 19762006. Entre la sombra de la dictadura y el futuro de la democracia. Rosario: Homo Sapiens Ediciones.

González, A. (2009). Políticas Archivísticas para la defensa de los Derechos Humanos. Actualización y ampliación del informe elaborado para Unesco y Consejo Internacional de Archivos (1995) sobre gestión de los archivos de los servicios de seguridad del estado de los desaparecidos: regímenes represivos. Fundación 10 de Marzo. http://www.ica.org/sites/default/files/Report_Gonzalez-Quintana_ES.pdf

Jelin, E. (2002). Introducción. Gestión política, gestión administrativa y gestión histórica: ocultamientos y descubrimientos de los archivos de la represión. En L. da Silva Catela, L. y E. Jelin (Comps.), Los archivos de la represión: documentos, memoria y verdad (pp. 15-38). Siglo XXI.

Kahan, E. (2007). ¿Qué represión, qué memoria? El 'archivo de la represión' de la DIPBA: problemas y perspectivas. Question. Revista Especializada en Periodismo y Comunicación, 1(16). http://www.memoria.fahce.unlp.edu.ar/art revistas/pr.11175/pr.11175.pdf

Ketelaar, E. (2001). Tacit narratives: the meaning of archives. Archival Science, 1(2), 131141. http://dx.doi.org/10.1023/A:1012226609547 
Lavintman, J., Pankonin, L. y López, H. (2017). Conocimiento histórico y justicia: el trabajo en el Archivo del Ejército Argentino. Aletheia, 7(14), 8-18. https://www.aletheia.fahce.unlp.edu.ar/article/view/ATH

Lettieri, L. y Agostini, V. (2018). La ESMA. Una mirada desde los documentos del Archivo General de la Armada. Hilos Documentales, 1(1), e005. https://revistas.unlp.edu.ar/HilosDocumentales/issue/view/456

Lvovich, D. y Bisquert, J. (2008). La cambiante memoria de la dictadura militar desde 1984: Discursos públicos, movimientos sociales y legitimidad democrática. UNGS/Biblioteca Nacional. https://www.ungs.edu.ar/cm/uploaded files/publicaciones/11 04\%20La\%20cam biante\%20memoria\%20de\%2ola\%20dictadura Lvovich.pdf

Markarian, V. (2016). Los documentos del pasado reciente como materiales de archivo. Reflexiones desde el caso uruguayo. Contemporánea, 7(7), 178-191.

Montero, A. S. (2012). iY al final un día volvimos! Los usos de la memoria en el discurso kirchnerista (2003-2007). Buenos Aires: Prometeo.

Muzzopappa, E. (2018). Secreto en el Estado. Buenos Aires: Teseo. https://www.teseopress.com/secretoenelestado

Nazar, M. (2007). Dictadura, archivos y accesibilidad documental. A modo de agenda. En Centro de Estudios Legales y Sociales (2007), Derechos humanos en Argentina. Informe 2007 por Centro de Estudios Legales y Sociales (pp. 413-424). Siglo XXI. http://www.cels.org.ar/common/documentos/ia_2007.pdf

Nazar, M. (2018). Archivos y Derechos Humanos: entre la historia, la memoria y la justicia. En S. Brunero y J. R., Vasallo (Comps.), El acceso a los archivos en la sociedad del conocimiento: apreciaciones desde la Argentina del siglo XXI. Córdoba: Redes. http://redarchiveroscordoba.com/wpcontent/uploads/2017/10/El-acceso-a-los-archivos-en-la-sociedad-delconocimiento.pdf

Ordenan la apertura de los archivos militares. (2006, 23 de marzo). Página 12. https://www.pagina12.com.ar/diario/elpais/subnotas/1-21308-2006-03-23.html

Perelmiter, L. (2016). Burocracia plebeya. La trastienda de la asistencia social en el Estado Argentino. UNSAM Edita.

Hallazgos

ISSN: 1794-3841 | e-ISSN: 2422-409X | DOI: https://doi.org/10.15332/2422409X

Vol. 18 N.० $36 \mid$ julio-diciembre del 2021 
Rico, Á. (2016). El actual malestar de los historiadores: entre la defensa del oficio y la responsabilidad política. Sobre archivos y repositorios documentales.

Contemporánea, $7(7), 178-191$.

Vázquez, M. (2014). 'Militar la gestión': una aproximación a las relaciones entre activismo y trabajo en el Estado a partir de las gestiones del gobierno de Cristina Fernández de Kirchner. Apuntes, 41(74), 71-102. DOI:

https://doi.org/10.21678/apuntes.74.703

Vélez Jiménez, P. (2013). Dictaduras, derechos humanos, memoria y archivos en Latinoamérica: el caso paraguayo. En G. Dalla, R. Piqueras y M. Tous (Coords.), América: poder, conflicto y política (pp. 763-782). Universidad de Murcia. https://goo.gl/bzzcC6

\section{Fuentes de archivo}

Ministerio de Defensa. Dirección de Derechos Humanos y Derecho Internacional Humanitario. (2010). Instructivo para la consulta de los acervos documentales de las Fuerzas Armadas. Buenos Aires: Ministerio de Defensa.

Ministerio de Defensa. Dirección de Derechos Humanos y Derecho Internacional Humanitario. (2015). Relevamiento y análisis documental en los Archivos de las Fuerzas Armadas 1976-1983. Buenos Aires: Ministerio de Defensa. 